\title{
Diálogos desde los estudios eidéticos: disposiciones, complejidades y temas pendientes
}

\section{Dialogues from eidetic studies: dispositions, complexities and pending topics}

\section{Glaudio Díaz Herrera}

Universidad de Talca (Chile)

cldiaz@utalca.cl

Fecha de recepción: 05/09/2018

Fecha de aceptación: 19/07/2019

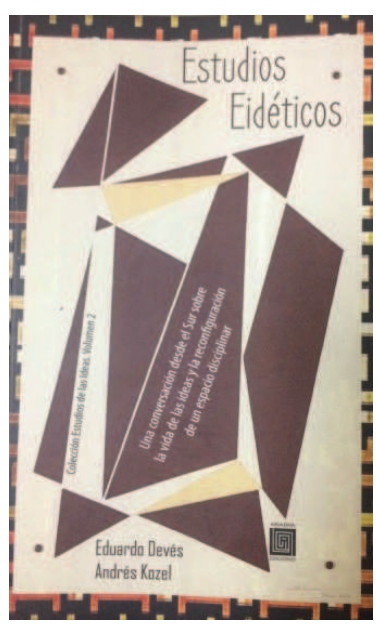

Reseña de la obra/ Book Review: Devés, Eduardoy Kozel, Andrés (2018). Estudios eidéticos. Una conversación desde el Sur sobre la vida de las ideas y la reconfiguración de un espacio disciplinar. Santiago de Chile: Ariadna ediciones, 315 p. ISBN: 978-956-393-532-5

Estamos frente a un texto elaborado por dos pensadores del sur de Nuestra América. Devés chileno y Kozel argentino poseen una relevante trayectoria en las áreas de los estudios de las ideas, a partir de sus instituciones de educación superior de referencia como el Instituto IDEAS de la Universidad de Santiago de Chile y la Escuela de Humanidades de la Universidad Nacional de San Martín respectivamente

Estudios Eidéticos es un esfuerzo teórico y metodológico escrito desde la camaradería de los autores, que nos recuerda a los clásicos escritos de una filosofía considerada para nosotros como clásica, debido a su influencia desde el pensamiento de occidente. 
El dialogo, una sistematización de conversaciones, encuentros y viajes intelectuales, se transforman en el mecanismo escogido por los autores para compilar esta obra con tintes reflexivos, teóricos, críticos y metodológicos. Los autores del texto acusan recibo de la necesidad de fortalecer el pensamiento latinoamericano, así como las formas en cómo proceder con el objeto de coadyuvar en el desarrollo de reflexiones en torno a las ideas, las cuales pudiesen ser consideradas como pensamiento periférico desde este lado del mundo nuestro americano.

Comenzando por una introducción elaborada por Kozel el texto se desarrolla en diez numerales, terminando con un epilogo a cargo de Devés y con tres anexos que resultan didácticos e interesantes en términos metodológicos.

Alunas de estas imágenes mencionadas, incluso se expresan plasmadas de puño y letra del propio Devés con el objeto de enunciar gráficamente algunos criterios de clasificación, circulación de redes intelectuales y cartografías eidéticas, dando un sustento visual y metodológico que nos orienta en la constitución de este tipo de conocimiento y reflexión eidética.

El texto se compone de diez numerales centrales comenzando con "Itinerarios, temas, relaciones"; "Los estudios eidéticos como propuesta de reconfiguración disciplinar"; "Entidades y sistemas eidéticos: definiciones y formas de clasificar"; "Ideas, realidad y sociedad: ¿una relación simbiótica?"; "Pensando los cambios en el nivel eidético"; "Redes intelectuales y circulación eidética"; "Desarrollo eidético y eidología aplicada"; "Más allá del centro"; "Inmersión en el futuro"; y por último, el décimo punto se denomina "Cajón de sastre".

El devenir de este libro, inicia con la inquietud de separarse de la filosofía clásica europea, para poder pensar América Latina en un contexto el cual carecía de elementos concretos de estudio y por tanto, habiendo mucho por estudiar y sistematizar respecto al pensamiento fuera de Europa.

Existe una necesidad en los estudios eidéticos de complementar enfoques de estudio, sin la necesidad de atomizar los fenómenos a disciplinas particulares y excluyentes. A su vez reconocen la dificultad metodológica de clasificación en los estudios eidéticos, privilegiando para esta misión, cartografías geográficas institucionales.

Desde el comienzo del texto Eduardo Devés es elemento fundamental como figura literaria, desde cuyo dialogo con Kozel orienta cercanías de enfoques teóricos y emocionales a la hora de trabajar las redes eidéticas. De esta forma repasa una importante cantidad de intelectuales dedicados a los estudios eidéticos y por cierto su propia vida, la que ha incidido poderosamente a la dedicación de estos estudios periféricos así como una disposición a pensar en grande.

A medida que avanza la lectura encontramos el desarrollo de una configuración disciplinar y multidisciplinar del área de estudio eidético. Esto permite una propuesta de esquematización curricular de un curso de estudios eidéticos nivel teórico y aplicado. 
Dentro de las propuestas de trabajo de esta reconfiguración ámbito disciplinar, emerge una hipótesis relevante, que apunta al precario desarrollo de la creatividad en el desarrollo del pensamiento sur americano. Sin embargo, sería necesario operativizar el concepto de "creatividad". Más allá de esto, Devés introduce otra hipótesis ligada al darwinismo eidético.

El autor Devés coloca en relevancia el uso metodológico, el cual aporta desde sus variadas aplicaciones para desentrañar la complejidad eidética de los estudios. Esto al alero de llamar a la construcción epistémica, que logre constituir un lenguaje común, lo que Devés denomina "maduración de un lenguaje" (pág. 44) y que resulta tener una connotación kuhniana que logre consensuar este lenguaje (Echeverría, 2015) tal como enfatizaremos más adelante.

En esta propuesta eidética Devés juega con las fronteras disciplinarias, haciendo un llamado a no mirar los estudios sobre las ideas desde una postura hegemónica. Invita de esta forma a tratar estos estudios eidéticos como "puntos de encuentro" (pág. 45).

A lo anterior, problematiza respecto al rol que juega la historiografía en los estudios eidéticos y su dificultad ante su uso aplicado en una historiografía positiva, como lo hubiese intentado el francés Comte avanzado su recorrido intelectual en los orígenes de la sociología (Ritzer, 2001).

Propone tener cuidado con la construcción eidética sospechosa, en cuanto es reduccionista a lo burdo en relación a extrapolación acrítica o bien, en términos de convergencia temporal y contextual. Por tanto se necesitaría de una propuesta de objetivos, enfoques, escuelas de los estudios de las ideas.

Por otro lado se dispone a superar la tensión entre método y disciplina, debido a que en la medida de lograr una construcción eidética de excelencia, no resulta significativa esta discusión. Para lo anterior, hay que apelar a metodologías múltiples, "sencillas, pragmáticas y factibles" (pág. 58), como la lectura crítica y comprensiva de textos y sus respectivas bibliografías, evitando así una sobre-sofisticación teórica o metodológica que termine por nublar la empiria desde el texto.

Desarrolla la definición de entidades eidéticas, como pilar de los estudios sobre las ideas, clasificando y articulando conceptualizaciones ad hoc a estos estudios, afinando en definitiva cómo comprender los estudios eidéticos en razón a la complejidad ontológica de la noción de idea.

Devés expone los tipos de clasificación que ha venido trabajando en pos de una mejor compresión y sistematización de los estudios. Desarrolla dentro del aspecto eidético diferencias sociales entre especies superiores e inferiores invitándonos a reflexionar desde incluso el plano biológico y cognitivo.

Los autores dan énfasis en la dialéctica de los estudios eidéticos, el cual se va vehiculizando necesariamente gracias a la agencia de intelectuales, sus viajes y las redes que se logran configurar y articular al alero de esto viajes intelectuales. 
Por otro lado exponen respecto al futuro de los estudios eidéticos que el autor propone como supuestos, que poseen la disposición a desarrollarse como elementos temáticos en el área de estudios en un futuro próximo.

Al leer el texto se agradece que Devés se asuma abiertamente como sujeto histórico para interactuar en este dialogo con su interlocutor. De esta forma nos invita a compenetrarnosconelrelato entérminosweberianos, desdelacomprensión overstehen. En este sentido, y entendiendo la complejidad conceptual en la definición de las ideas, esta puede ser leída como una suerte de tipos ideales weberianos (Weber, 2005).

Devés nos tiene acostumbrados a realizar una lectura crítica, disponiéndonos a sacar a la luz un cúmulo de capital cultural (Bourdieu, 2008) que permita alcanzar una comprensión cabal de los autores y regiones a los cuales se refiere en desarrollo del texto.

Desde un punto de vista crítico del texto, se puede señalar que el desafío de la obra radica en el tránsito por una constante tensión que emerge a nivel antropológico cultural, metodológico y discursivo.

Lo anterior invita a acercarse al texto con la idea de poder complementarse desde dos perspectivas centrales, que pueda ser leída en clave de teoría sistémica, y por otro lado; a razón de una necesidad de analizar las ideas desde una complejidad que circunda en la apropiación y estudio del lenguaje aunque no en términos exclusivamente lingüísticos, sino que antropológicos del lenguaje.

En este sentido el estudio del pensamiento periférico de las ideas, suponemos podría generar representaciones reflexivas que están sujetas a un pensamiento inminentemente antropológico y por tanto culturalmente periférico. Es decir, no sería de extrañar que ideas, pensamientos, reflexiones, entre otros, pudiesen carecer de una comprensión epistémica y conceptual si no hay una apropiación del lenguaje a escala nativa. Esto vendría siendo un dilema que perfectamente podríamos encontrarnos durante el desarrollo del pensamiento eidético subalterno y situado en su geografía lingüística y dialéctica en particular.

Esto nos invita a seguir desarrollando metodologías que logren superar estas brechas de significados conceptuales y discursivos, a partir de la reflexión epistémica de una lengua de origen. Lo que nos invita a pensar ¿cómo pensar eficazmente un sistema cultural si no conozco su lenguaje y/o dialecto específico situado?

Entiéndase entonces que desde el pensamiento periférico, pudiese existir una noción que se encuentre enquistada por ejemplo en el mundo indígena, y puede que no posea alcances de sistematización escrita, conceptual o epistémica del pensamiento de orden sub periférico dentro de esta misma periferia.

Lo anterior invita hacia una disposición de comprender los estudios eidéticos, desde la discusión de posturas antropológicas emic o etic (Harris, 1999), lo que puede conllevar a la configuración de cosmovisiones o cosmogonías originales, pero desde mirada externa y que potencialmente pueda ser tratada desde otro nivel estamental si lo analizamos en términos weberainos. 
En este sentido Devés plantea que "La forma privilegiada de formularse de las entidades eidéticas es "en", "a través" de las lenguas, pero no es su forma exclusiva. El lenguaje de los gestos, los sonidos no vocalizados, la plástica y la cultura material también permiten o contribuyen a expresar entidades eidéticas, aunque de manera menos apropiada" (pág. 65).

Por tanto existe una compleja relación entre el lenguaje y su uso como productor de conocimiento. Esto en razón al válido cuestionamiento frente a la internalización del lenguaje de parte de estos productores de conocimientos quienes no poseen una interiorización de este lenguaje.

Es sabido que la dificultad que presenta el lenguaje en un mundo globalizado y en una sociedad del conocimiento, es justamente la capacidad real de traducción de ideas, sobre todo cuando nos referimos a pensamiento periférico, con sus respectivos dialectos o idiomas periféricos, lo que invita a abrir un mundo de interpretaciones sujetas a contextualización de tipo cultural expresadas agencialmente a nivel material e inmaterial como categoría cultural.

En honor a la naturaleza temática del texto, si bien es un excelente insumo para acercarse didáctica aunque sujeto a una vasto nivel de complejidad conceptual en los estudios eidéticos, podemos dilucidar que quedan pendientes otros elementos que se hacen necesarios desarrollar -que si bien los autores anuncian durante el relato-, terminan siendo relevantes para profundizar los estudios eidéticos en honor al valor multidisciplinar de estos estudios.

Hay que destacar la capacidad propositiva de Devés a la hora de sistematizar el pensamiento eidético, que logre en definitiva sustentarse a nivel metodológico y teórico en conceptualizaciones que requerirían una constante profundización. De esta forma el autor elabora estaciones (momentos) dentro del proceso de circulación de ideas, como las propuestas en el trabajo de la teología de la liberación en Sri Lanka (Devés, 2017).

En este sentido Devés se esfuerza en crear modos de lectura, cada uno de ellos dueños de prácticas lectoras con disposiciones teleológicas en su quehacer.

Una de las dificultades del texto, es la importante cantidad de acervo conceptual que poseen los estudios eidéticos, tornando de complejidad su lectura para quienes no están asimilados a este lenguaje, situación que comparte en gran medida un quehacer desde la teoría de sistemas y gran parte de sus autores relevantes.

Según lo anterior, el texto en su afán orientador a los estudios eidéticos resulta pertinente leerlo en complementación con una lectura en clave sistémica. En el entendido que esta complementariedad teórica no es mencionada por los autores durante el desarrollo del texto, resultando clarificador su uso complementario para acercarnos a niveles conceptuales comunes. Esto ayudaría a entrar a este mundo de los estudios de las ideas bajo un sustento teórico que acople esta perspectiva de estudios de mejor forma con las ciencias sociales. 
Existen así conceptos entre estas posturas teóricas que posee grados de similitud: energía, ecosistema, sistema, retroalimentación, observación de segundo orden, modelo de input y output (Arnold \& Osorio, 1998) entre otros conceptos, los que pueden verse interpretados de una u otra forma en la conceptualización y lenguaje desde el texto de estudios eidéticos.

Otro de los puntos álgidos del texto en razón a su forma de escritura en dialogo, es que si bien lo hace interesante, al mismo tiempo poseen esta capacidad de abrir temáticas que lamentablemente por espacio o línea editorial de la conversación terminan por no ser desarrollados.

Por otro lado, el texto hace un esfuerzo en profundiza respecto a la naturaleza ontológica de lo eidético a partir de la noción de "eida" y de las formas en cómo se puede expresar dentro del mismo texto. Sin lugar a dudas esto resulta relevante a hora de reflexionar en la necesidad de un consenso epistemológico a la usanza kuhniana para establecer un lenguaje común que los autores ya anuncian en el relato.

La conversación pierde peso fenomenológico al no profundizar tampoco en el sentido, algo que incluso Kozel advierte. En este aspecto, y aunque Devés asume que perdería direccionalidad la conversación central del texto (las ideas), el trabajo en sí mismo invita a adentrarse en el sentido tal como nos exigiría Husserl(Echeverría, 2015).

Finalmente es un texto interesante, lleno de complejidad discursiva con disposición a clarificar cada vez más lo referente a los estudios eidéticos y que intenta a su vez no desviarse de tema central que convoca el texto. Sin embargo, esta misma tensión emergente entre diversas temáticas que se van desprendiendo durante la conversación, sin lugar a dudas amerita profundizar en futuros volúmenes de la colección Estudios de las Ideas de Ariadna Ediciones.

\section{BIBLIOGRAFÍA}

Arnold, M., \& Osorio, F. (1998). Introducción a los conceptos básicos de la teoría general de sistemas. Cinta moebio, 3, 40-49.

Bourdieu, P. (2008). capital cultural, escuela y espacio social. México: Ediciones Siglo XXI.

Devés, E. (2017). La teología asiática de la liberación: un caso de recepción, apropiación y reelaboración de ideas. Universum, 32(1), 213-230.

Echeverría, R. (2015). El Búho de Minerva. Santiago: JCSáez.

Harris, M. (1999). El desarrollo de la teoría antropológica. Una historia de las teorías de la cultura. México D.F: Siglo XXI.

Ritzer, G. (2001). Teoría sociológica clásica. España: McGraw-Hill .

Weber, M. (2005). Economía y Sociedad. México: Editorial Fondo de Cultura Económica 